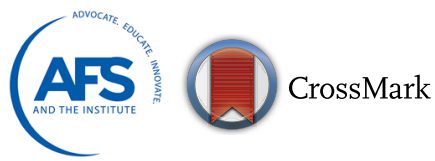

\title{
TECHNOLOGY OF ALLOY LAYERS ON SURFACE OF CASTINGS
}

\author{
Tomasz Wróbel (1), Natalia Przyszlak (i), and Agnieszka Dulska (i) \\ Department of Foundry Engineering, Silesian University of Technology, Gliwice, Poland
}

Copyright () 2019 The Author(s)

https://doi.org/10.1007/s40962-018-00304-x

\begin{abstract}
The paper presents a technology of layered castings based on the use of a method of mould cavity preparation via spatial skeleton insert. The insert was created as a result of application of $3 D$ printing selective laser melting method. The studied spatial skeleton insert, made from CP2 Ti powder, was placed into the mould cavity directly before

solid spatial skeleton insert and liquid alloy allowed for the production of a casting of pearlitic grey cast iron with flake graphite, containing a surface layer reinforced with titanium carbides. In consequence, a local increase in hardness was obtained and, moreover, an increase in abrasive wear resistance of the whole surface layer of the casting.
\end{abstract} pouring grey cast iron. The scope of the conducted studies covered metallographic research using a light microscope and scanning electron microscope with EDS analysis, hardness measurements and abrasive wear resistance tests. The obtained results show that the interaction between the
Keywords: alloy surface layer, insert, 3D printing, titanium, grey cast iron

\section{Introduction}

The technology of layered castings becomes more and more popular, particularly when the criterion for highly usable properties concerns only the working surface layer and the rest of the casting is only a base part that is not exposed to a direct influence of factors causing abrasive or corrosion wear. This technology is the most economical way of enriching the surface of castings, as it allows for the production of layered elements directly in the casting process. Therefore, this technology can be significantly competitive to commonly used technologies of surfacing by welding, thermal spraying and surface heat or thermochemical treatment. ${ }^{1,2}$ In general, the technology of cast bimetals containing a working layer and a base part is carried out based on three systems, considering the physical state of the combined materials, i.e. liquid-liquid, ${ }^{3,4}$ solid-solid ${ }^{5}$ and liquid-solid. ${ }^{6-15}$

An example of the former is a technology in which two independent gating systems are made, which guarantee a

This paper is an invited submission to IJMC selected from presentations at the 73rd World Foundry Congress, held September 23 to 27, 2018, in Krakow, Poland, and has been expanded from the original presentation. two-stage filling of the sand mould cavity. According to this manufacturing method, the bimetallic elements of hammer ${ }^{3}$ or ball $^{4}$ mills are cast in material configurations of an abrasive wear resistant chromium cast iron working layer with a ductile low-carbon cast steel base, whereas application of the second technology allows to obtain relatively small elements in steel-cast iron configuration. ${ }^{5}$ Moreover, the basis of the technology of layered castings made using the liquid-solid system is a so-called method of mould cavity preparation. In this manufacturing method, the element that enriches the surface of the casting is placed in a mould in the form of a granular ${ }^{6-9}$ or monolithic $^{10-15}$ insert, directly before molten metal is poured. According to this manufacturing method, the bimetallic elements of runners ${ }^{6,7}$ or lining plates ${ }^{13,14}$ are cast in material configurations, connecting an abrasion and corrosion resistant high-alloy stainless steel or $\mathrm{Cr}$ base alloy working layer with a grey cast iron or carbon cast steel base.

The paper presents the use of the technology of mould cavity preparation in order to obtain layered castings with application a new insert shape, i.e. a spatial skeleton manufactured using 3D printing based on selective laser melting (SLM) method. Selective laser melting ${ }^{16}$ is an 
additive manufacturing method that uses a laser in an inert atmosphere to selectively melt layers of loose metal powder into a solid, building a part layer by layer, starting from the bottom.

\section{Experimental Procedure}

The aim of the study was to manufacture a layered casting using mould cavity preparation method with the use of an insert created via SLM method. The applied spatial skeleton insert made from CP2 Ti powder is presented in Figure 1. The skeleton structure of the insert was made by

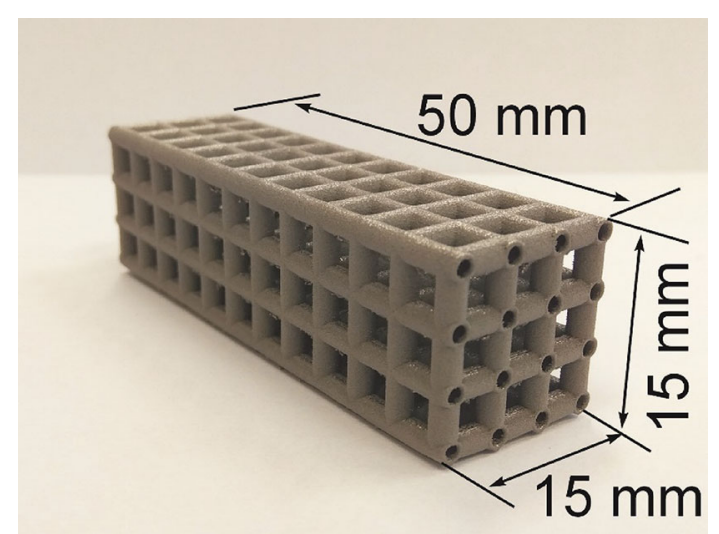

Figure 1. View of the 3D printing spatial skeleton CP2 Ti insert.

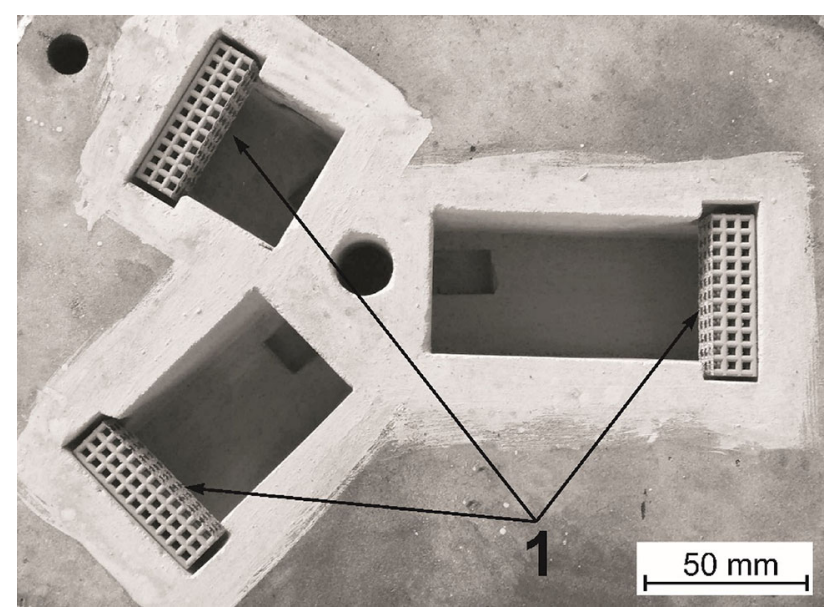

Figure 2. View of the bottom part of a sand mould with 3D printing spatial skeleton CP2 Ti inserts (1) placed in its cavity. connecting rods of circular cross section and $3 \mathrm{~mm}$ diameter, arranged vertically and horizontally. Additionally, the connecting rods were empty inside and their internal diameter was $1.5 \mathrm{~mm}$.

Inserts of this type have been placed in the sandmix with bentonite mould cavities with no preheating, as shown in Figure 2. Then, the mould with inserts was filled with pearlitic grey cast iron including flake graphite. The pouring temperature was set at approx. $1400{ }^{\circ} \mathrm{C}$. As a result of this experimental plan, layered castings with ratios of thickness between the grey cast iron base and the $\mathrm{Ti}$ insert of $2: 1,3: 1$ and $4: 1$ were produced.

The chemical compositions of used grey cast iron were determined by application of LECO GDS500A emission spectrometer and LECO CS-125 analyser (Table 1).

Then, metallographic macro- and microscopic examinations were carried out. NIKON light microscope optical microscopy (OM) and Phenom ProX scanning electron microscope (SEM) with microanalysis of the chemical composition energy dispersive microscopy (EDS) were used to carry out a microstructure research. Measurements of microhardness were done using FM 700 Future-Tech (HV0.1). Moreover, tests of abrasive wear resistance using pin-on-disc method according to Reference ${ }^{17}$ were conducted. In this method, the rotational speed of disc with the sample was $150 \mathrm{rpm}$, while the rotational speed of the counter specimen with $\mathrm{SiC}$ (abrasive paper) was $400 \mathrm{rpm}$. The obtained results of abrasive wear resistance tests for the studied layered castings were compared with results obtained for other metallic materials, i.e. pearlitic grey cast

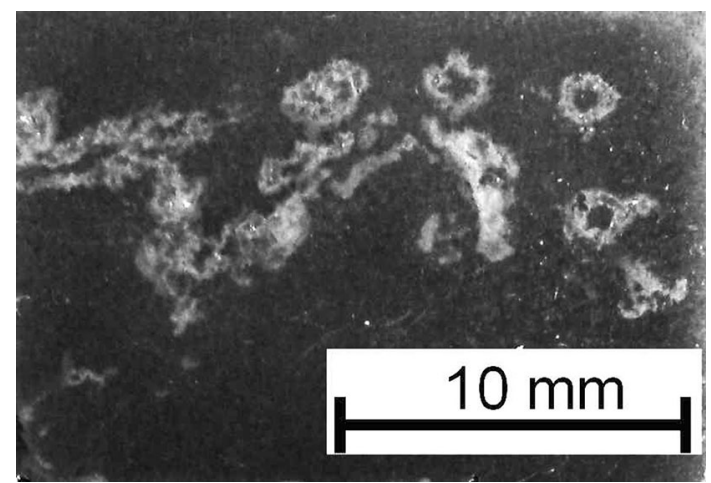

Figure 3. Example macrostructure of a working surface of layered casting reinforced by a spatial skeleton CP2 Ti inserts.

Table 1. Chemical Composition of Grey Cast Iron Base of Layered Casting

\begin{tabular}{|c|c|c|c|c|c|c|c|c|c|c|}
\hline C & $\mathrm{Mn}$ & $\mathrm{Si}$ & $\mathrm{Cr}$ & $\mathrm{Ni}$ & $\mathrm{Cu}$ & $\mathrm{Ti}$ & $\mathrm{V}$ & $\mathrm{P}$ & $\mathrm{S}$ & $\mathrm{Fe}$ \\
\hline \multicolumn{11}{|c|}{ Elements content (wt\%) } \\
\hline 3.20 & 0.60 & 2.10 & 0.25 & 0.05 & 0.20 & 0.01 & 0.01 & 0.11 & 0.08 & Rest \\
\hline
\end{tabular}


iron with flake graphite of EN-GJL-HB215 grade, highchromium white cast iron of EN-GJN-HV600(XCr18) grade and hardened low-alloyed steel Creusabro 8000 of hardness 450HV0.1.

\section{Results and Discussion}

In the first stage of the study, it was found that in the case of layered castings with the ratio of thickness between the grey cast iron base and the Ti insert equals $2: 1$ and 3:1, the skeleton was not completely filled by liquid cast iron and the quality of the bond between the two analysed materials

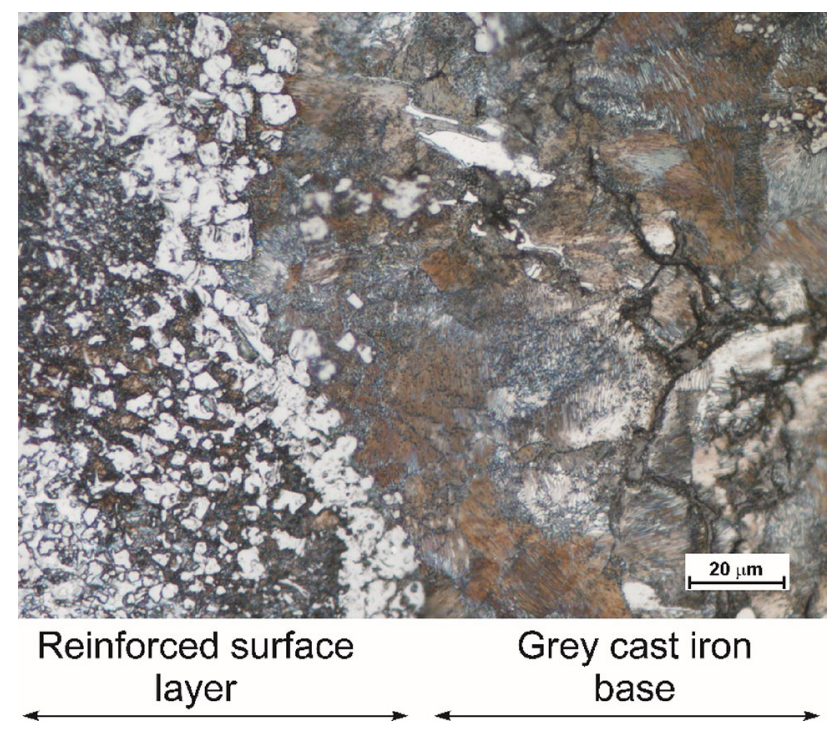

Figure 4. Microstructure of the bonding area between a surface layer reinforced by a spatial skeleton CP2 Ti insert and grey cast iron base, mag. $\times 500$, OM.

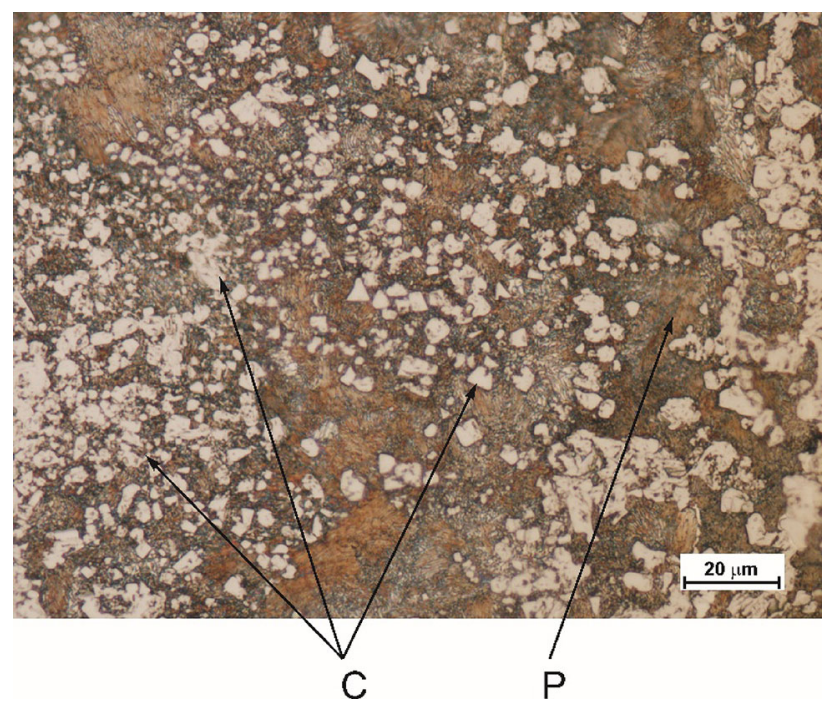

Figure 5. Microstructure of a working surface of layered casting reinforced by a spatial skeleton CP2 Ti insert, $C$-titanium carbides, $P$-pearlite, mag. $\times 500$, OM. was relatively low, whereas in case of thickness ratio 4:1, the insert was fully filled with liquid cast iron and good bond between the two parts of a layered casting (Figure 3) was achieved. This results from the fact that the thickness ratio of at least 4:1 makes it possible to overcome cooling impact of the insert effect on the liquid metal that solidifies

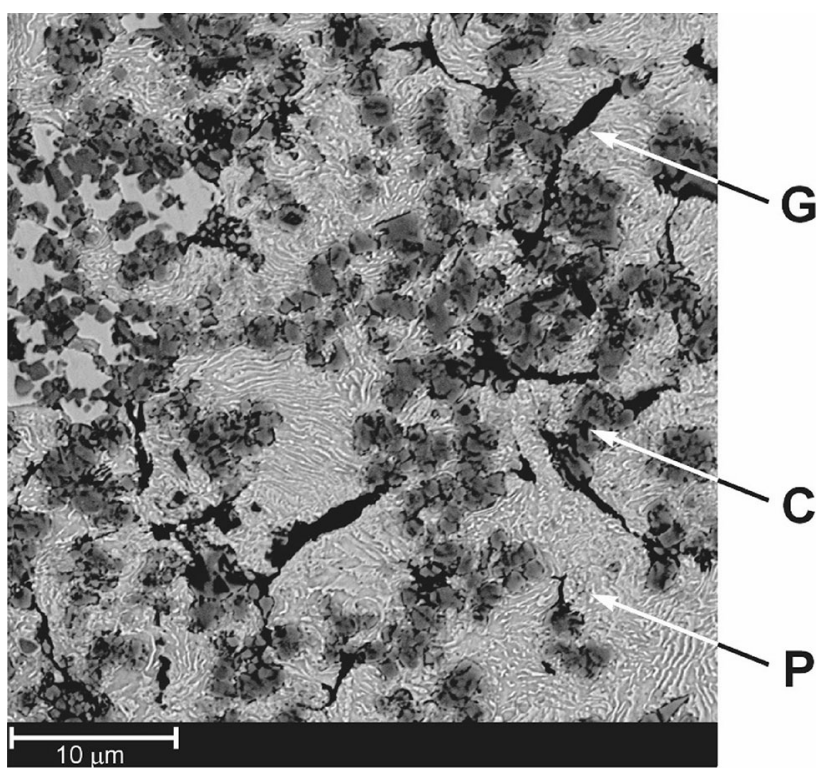

Figure 6. Titanium carbides in pearlitic matrix in the microstructure of a working surface of a layered casting reinforced by a spatial skeleton CP2 Ti insert, Ctitanium carbides, $P$-pearlite, $G$-flake graphite, mag. $\times 6200$, SEM.

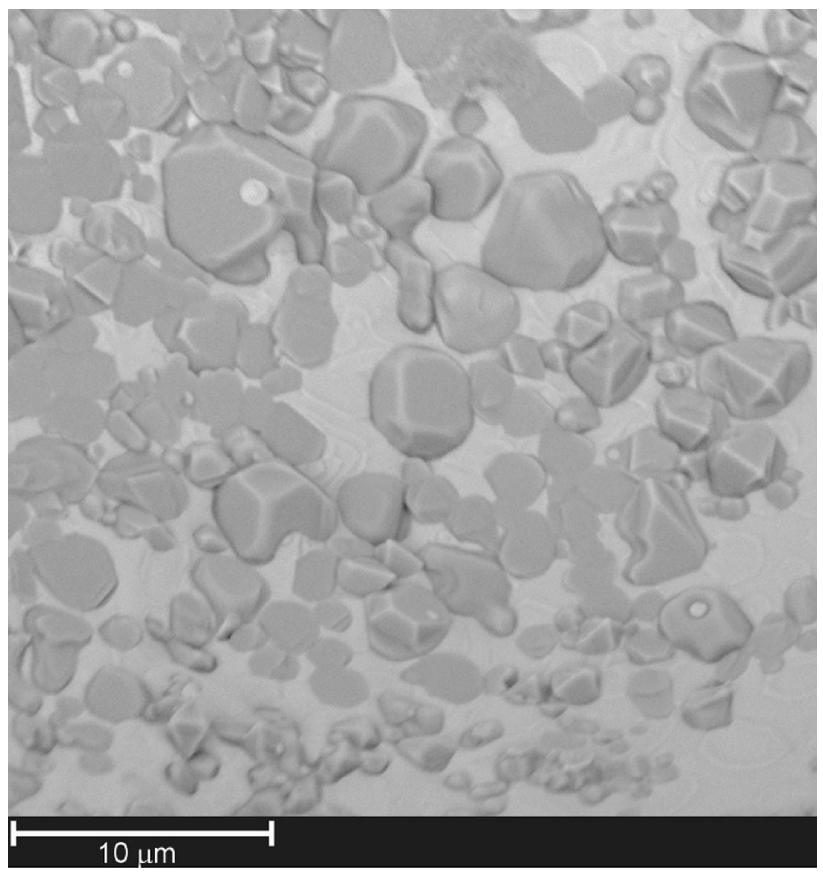

Figure 7. Microstructure of a working surface of layered casting containing titanium carbides in pearlitic matrix, mag. $\times 8400$, SEM. 
Table 2. Result of EDS Analysis in Measuring Points from Figure $8 a$

\begin{tabular}{|c|c|c|c|c|c|c|}
\hline \multirow[t]{3}{*}{ No. of point } & \multicolumn{6}{|c|}{ Element content } \\
\hline & \multicolumn{2}{|l|}{$\mathrm{Ti}$} & \multicolumn{2}{|l|}{ C } & \multicolumn{2}{|l|}{$\mathrm{Fe}$} \\
\hline & wt\% & at.\% & wt\% & at. $\%$ & $w t \%$ & at. $\%$ \\
\hline 1 & 40.25 & 71.52 & 58.62 & 26.13 & 1.13 & 2.34 \\
\hline 2 & 43.27 & 73.27 & 55.04 & 23.39 & 1.70 & 3.35 \\
\hline
\end{tabular}

in the mould. Moreover, as shown in Figure 3, the material of the spatial skeleton insert is partially dissolved in the grey cast iron matrix. Probably the degree of dissolving of the insert depends on parameters of a casting process, mainly on the pouring temperature of grey cast iron. Therefore, the thickness on cross section of obtained reinforced working layer is irregular.
Figures 4, 5, 6 and 7 present an example microstructure of the surface layer of casting. As a result of reaction between liquid cast iron solidified in the sand mould and Ti spatial skeleton insert, a precipitation of titanium carbides in the microstructure of the reinforced surface layer of the casting (Figure 4) may be observed. As a consequence of diffusion process in a high-temperature zone, the atoms of carbon are set in octahedral interstice of titanium atoms, which is accompanied by precipitation of carbides. The concentration of carbides decreases together with an increase in the distance from the insert. Moreover, the carbides have different sizes (approx. from 2 to $7 \mu \mathrm{m}$ ) and shapes. Example titanium carbides in pearlitic matrix obtained in the surface layer of the casting are presented in Figures 5, 6 and 7.

Furthermore, on the basis of EDS analysis (Table 2) carried out in selected points presented in Figure 8, it can be found that non-stoichiometric $\mathrm{TiCx}$ carbides were produced in the microstructure of the reinforced surface layer.

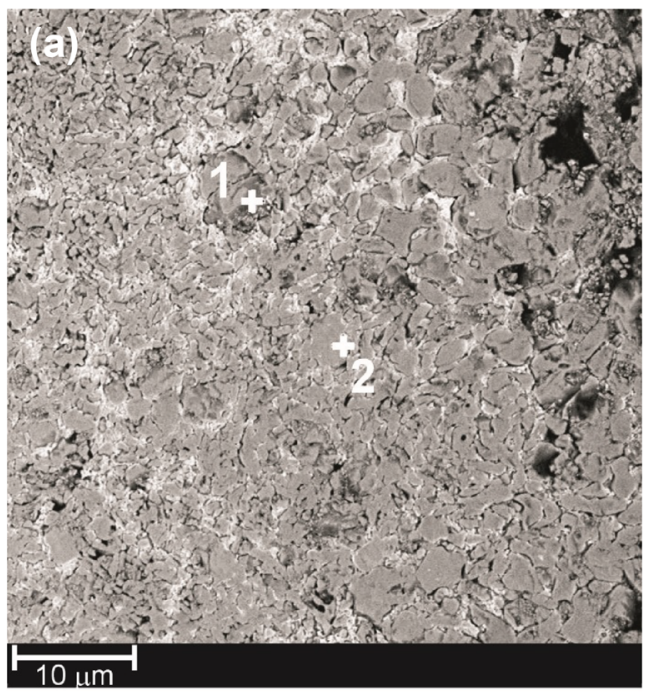

(b)

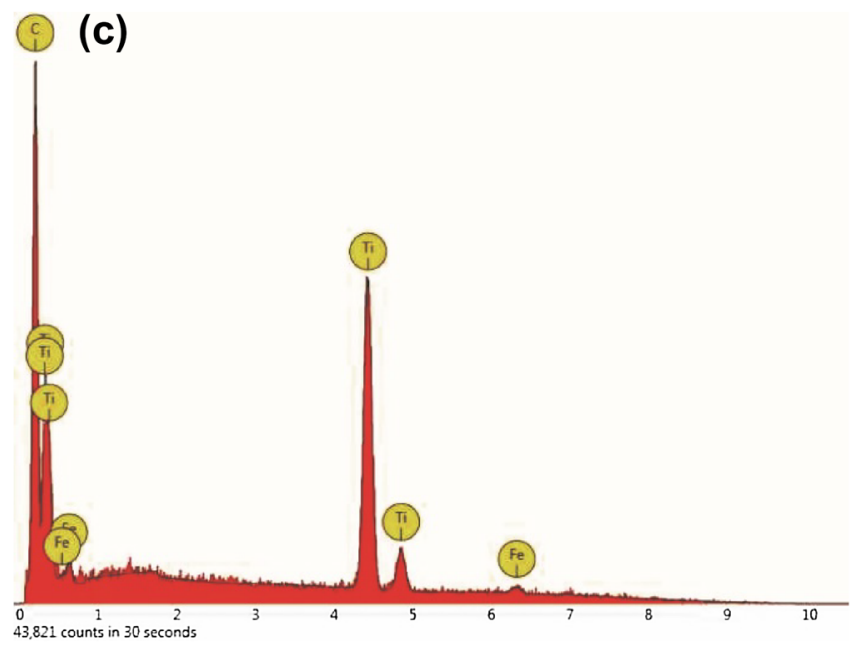

2

Figure 8. Non-stoichiometric TiCx carbides in the microstructure of a working surface of a layered casting: (a) mag. $\times 6000$, SEM, (b) EDS X-ray spectrum of point 1 from (a), (c) EDS X-ray spectrum of point 2 of (a). 
(a)

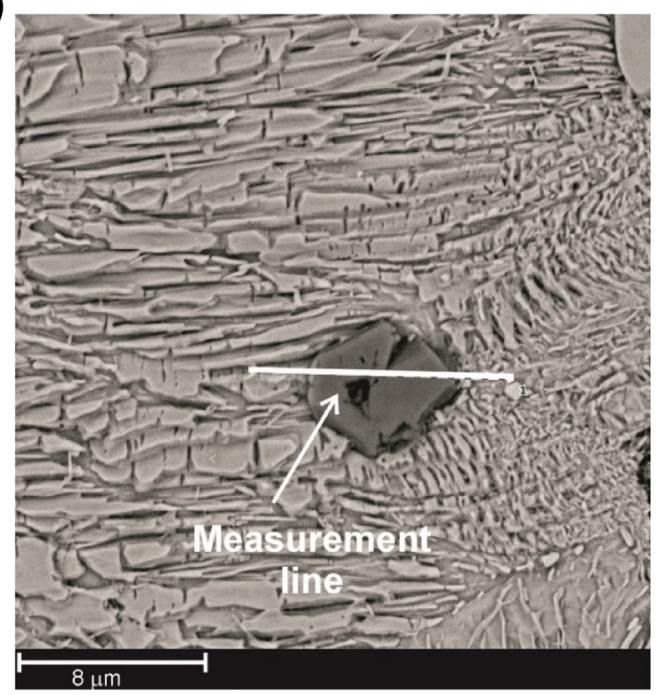

(c)

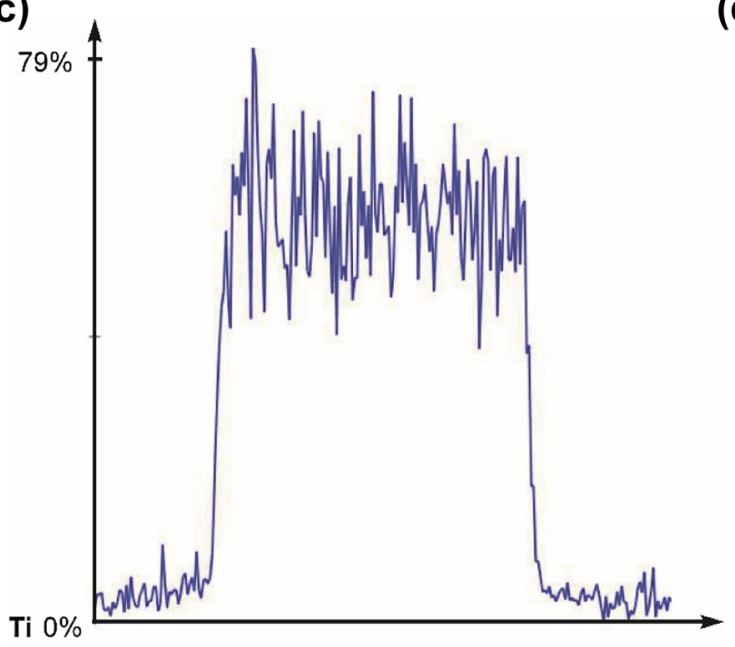

(b)

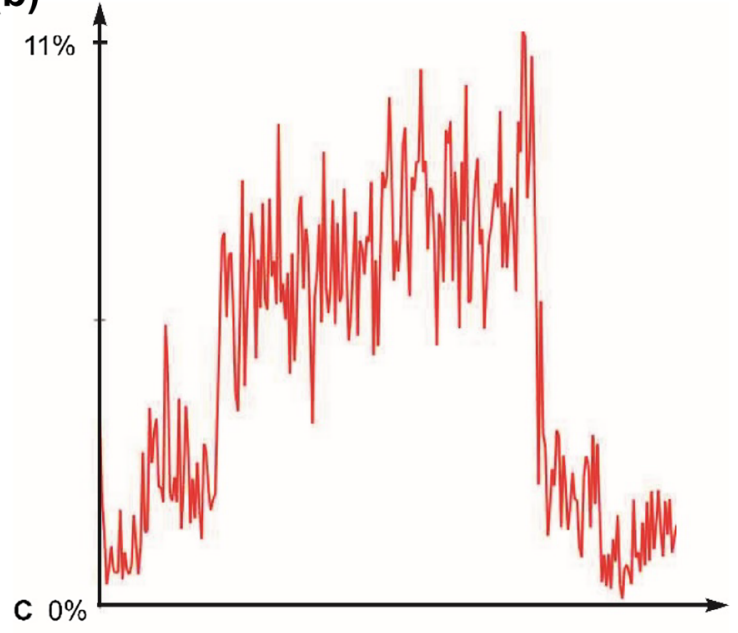

(d)

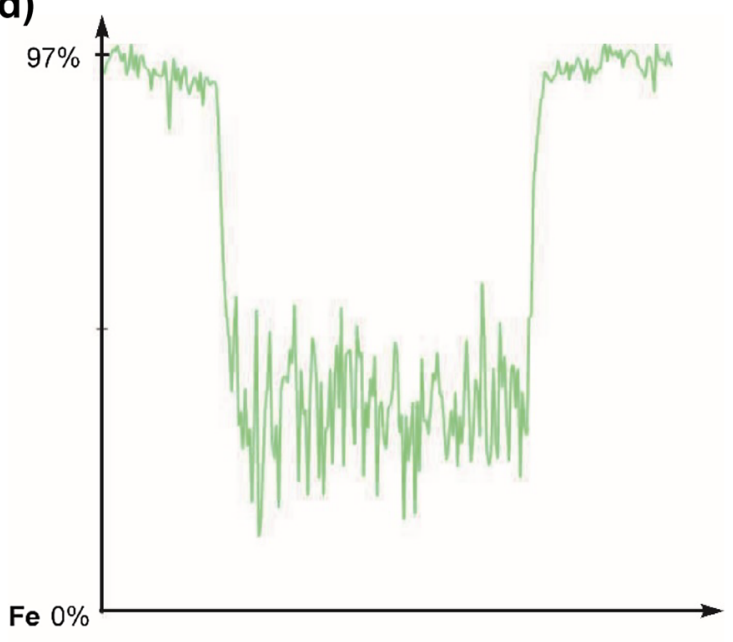

Figure 9. Result of linear EDS analysis of example titanium carbide in the microstructure of a working surface of a layered casting: (a) the microstructure of the studied area, mag. $\times 10,000$, SEM (b) distribution of C, (c) distribution of $\mathrm{Ti}$, (d) distribution of Fe.

The obtained results of the metallographic researches also confirm that each reinforced layer is divided into two areas, i.e. an internal with a small amount of titanium carbides and an external with a large amount of titanium carbides. The internal area was created in the empty space inside the rod, whereas the external layer was created as a result of the reaction between liquid cast iron and the wall of the rod. The obtained carbides are very tightly bonded to the grey cast iron matrix, as shown in Figure 9. Therefore, it can be considered that the reinforcing surface of the studied layer has a form of an in situ composite.

The obtained results of the study of the usable properties show that the hardness of the reinforced working layer of the casting is varied and depends on the concentration of titanium carbides. Therefore, the internal area with a small amount of carbides is characterised by a hardness of approx. 700HV0.1, while the external area with a large amount of carbides features hardness of approx. 900HV0.1.

The obtained local increase in hardness increases in the abrasive wear resistance of the whole surface layer of the casting, as shown by the results presented in Table 3 . Wear resistance of the studied layered casting is larger than the wear resistance of the compared cast irons and steel. Similar results related to the increase in the abrasive wear resistance along with the increase in hardness were also obtained in studies described in other papers ${ }^{7-9}$ concerning the reinforced surface layers on grey cast iron castings. 


\section{Table 3. Result of Abrasive Wear Resistance Measurements}

Type of sample Mass loss of sample (g)

Average mass loss of sample

(g)

\begin{tabular}{|c|c|c|c|c|c|}
\hline Layered casting & 0.012 & 0.021 & 0.013 & 0.014 & 0.014 \\
\hline $\begin{array}{l}\text { Grey cast iron } \\
\text { EN-GJL-HB215 }\end{array}$ & 0.262 & 0.201 & 0.203 & 0.192 & 0.281 \\
\hline $\begin{array}{l}\text { High-chromium } \\
\text { white cast iron } \\
\text { EN-GJN- } \\
\text { HV600(XCr18) }\end{array}$ & 0.043 & 0.034 & 0.031 & 0.061 & 0.062 \\
\hline $\begin{array}{l}\text { Hardened low- } \\
\text { alloyed steel } \\
\text { Creusabro } \\
8000\end{array}$ & 0.092 & 0.053 & 0.061 & 0.082 & 0.071 \\
\hline
\end{tabular}

\section{Conclusions}

Based on the conducted studies, the following conclusions have been formulated:

1. There is a possibility to reinforce a surface layer of a grey cast iron casting by the use of a spatial skeleton insert $\mathrm{Ti}$ obtained via 3D printing method as a part of the method of mould cavity preparation; however, the quality of obtained layered casting strongly depends on the casting parameters.

2. The working layer obtained by using the studied technology does not guarantee uniform thickness on cross section and distribution of reinforcing titanium carbides on the surface of the casting.

3. As a result of reaction between CP2 Ti insert and liquid cast iron, titanium carbides are obtained. Their presence in the microstructure of the working surface layer guarantees an increase of hardness and abrasive wear resistance of the casting.

4. Because promising results were obtained, subsequent research will present the influence of the pouring temperature of cast iron on the microstructure and usable properties of a surface layer reinforced by titanium carbides in the analysed technology of layered casting.

\section{Acknowledgements}

This paper is an invited submission to IJMC, selected from presentations shown at Session "Poster Display I" of the 73rd World Foundry Congress, held 23-27 September 2018, in Krakow, Poland, and has been expanded compared to the original presentation.
Open Access This article is distributed under the terms of the Creative Commons Attribution 4.0 International License ( http://creativecommons.org/licenses/by/4.0/), which permits unrestricted use, distribution, and reproduction in any medium, provided you give appropriate credit to the original author(s) and the source, provide a link to the Creative Commons license, and indicate if changes were made.

\section{REFERENCES}

1. M. Żuk, J. Górka, R. Dojka, A. Czupryński, Repair welding of cast iron coated electrodes. IOP Conf. Ser. Mater. Sci. Eng. 227, 012139 (2017). https://doi.org/10.1088/1757-899X/227/1/012139

2. A. Smalcerz, J. Barglik, D. Kuc, K. Ducki, S. Wasinski, The microstructure and mechanical properties of cylindrical elements from steel 38Mn6 after continuous induction heating. Arch. Metall. Mater. 61(4), 1969-1973 (2016). https://doi.org/10.1515/amm-2016-0318

3. S. Žic, I. Džambas, M. Konić, Possibilities of implementing bimetallic hammer castings in crushing industries. Metalurgija 48(1), 51-54 (2009)

4. X. Xiao, S. Ye, W. Yin, X. Zhou, Q. Xue, High Cr white cast iron/carbon steel bimetal liner by lost foam casting with liquid-liquid composite process. China Foundry 9(2), 136-142 (2012)

5. F. Calvo, A. Ureña, M. Gomez De Salazar, F. Molleda, Difusion bonding of grey cast iron to Armco iron and a carbon steel. J. Mater. Sci. Lett. 24, 4152-4159 (1989)

6. J. Szajnar, A. Dulska, T. Wróbel, J. Suchoń, Diffusion of $\mathrm{C}$ and $\mathrm{Cr}$ during creation of surface layer on cast steel casting. Arch. Metall. Mater. 59(3), 1085-1087 (2014). https://doi.org/10.2478/amm-2014-0186

7. J. Szajnar, A. Walasek, C. Baron, Tribological and corrosive properties of the parts of machines with surface alloy layer. Arch. Metall. Mater. 58(3), 931-936 (2014). https://doi.org/10.2478/amm-2013-0104

8. E. Olejnik, Ł. Szymański, P. Kurtyka, T. Tokarski, B. Grabowska, P. Czapla, Hardness and wear resistance of $\mathrm{TiC}-\mathrm{Fe}-\mathrm{Cr}$ locally reinforcement produced in cast steel. Arch. Foundry Eng. 16(2), 89-94 (2016). https://doi.org/10.1515/afe-2016-0032

9. R. Zhou, Y. Jiang, D. Lu, The effect of volume fraction of WC particles on erosion resistance of WC reinforced iron matrix surface composites. Wear 255(1-6), 134-138 (2003). https://doi.org/10.1016/S0043-1648(03)00290-4

10. B. Xiong, C. Cai, B. Lu, Effect of volume ratio of liquid to solid on the interfacial microstructure and mechanical properties of high chromium cast iron and medium carbon steel bimetal. J. Alloys Compd. 509(23), 6700-6704 (2011). https://doi.org/10.1016/j.allcom.2011.03.142 
11. T. Wróbel, Characterization of bimetallic castings with an austenitic working surface layer and an unalloyed cast steel base. J. Mater. Eng. Perform. 23(5), 1711-1717 (2014). https://doi.org/10.1007/s11665-014-0953-4

12. X. Zhi, Y. Han, J. Liu, M. Zhao, S. Ma, Casting process optimization of a bimetal wear-resistant block using liquid-solid processing. Int. J. Mater. Res. 105(10), 953-960 (2014). https://doi.org/10.3139/146.111109

13. T. Wróbel, J. Szajnar, Bimetallic casting: ferritic stainless steel-grey cast iron. Arch. Metall. Mater. 60(3), 2361-2365 (2015). https://doi.org/10.1515/amm-2015-0385

14. T. Wróbel, J. Wiedermann, P. Skupień, Bimetallic castings in a chromium-nickel stainless steel working surface layer configuration with a grey cast iron base. Trans. Indian Inst. Met. 68(4), 571-580 (2015). https://doi.org/10.1007/s12666-014-0488-2

15. R. Mola, T. Bucki, Characterization of the bonding zone in a ZE41/AlSi12 joint fabricated by liquid-solid compound casting. Arch. Foundry Eng. 18(2), 203-208 (2018). https://doi.org/10.24425/122529

16. M. Król, T. Tański, Surface quality research for selective laser melting of Ti-6Al-4 V alloy. Arch. Metall. Mater. 61(3), 945-950 (2016). https://doi.org/10.1515/amm-2016-0213

17. A. Studnicki, R. Dojka, M. Gromczyk, M. Kondracki, Influence of titanium on crystallization and wear resistance of high chromium cast iron. Arch. Foundry Eng. 16(1), 117-123 (2016). https://doi.org/10.24425/122503 